DOI: $10.18027 / 2224-5057-2017-7-3 s 1-57-60$

Цитирование: Петухова И. Н., Соколовский А. В., Григорьевская З. В., Багирова Н. С., Терещенко И. В. и др. Инфекции, связанные с установкой инородных материалов (протезы, сетки, импланты) // Злокачественные опухоли. - 2017. - Т. 7. - №3, спецвыпуск 1. - С. 57-60.

\title{
Инфекции, связанные с установкой инородных материалов (протезы, сетки, импланты)
}

\author{
И. Н. Петухова' \\ ${ }^{1}$ Национальный медицинский исследовательский центр онкологии им. Н. Н. Блохина Минздрава России, г. Москва \\ ${ }_{2}^{2}$ ГБУЗ г. НКБ им. Братьев Бахрушиных ДЗ г. Москва \\ зГБПОУ дЗМ Медицинский Колледж № 1, г. Москва
}

Резюме: В эпоху применения различных металлических и других устройств с лечебной целью отмечается появление инсрекций, связанных с установкой и длительным нахождением этих устройств (англ. - device) в организме человека. Помимо широкораспространенных катетер-ассоциированных инфекций (КАИ) кровотока и КАИ мочевых путей, а также инфекционных эндокардитов, связанных с протезированием клапанов, все большее значение приобретают перипротезные инфекции (в ортопедии, онкоортопедии), инфекции, связанные с установкой сеток (в хирургии), стентов (в сосудистой хирургии и др.), водителей ритма (в кардиохирургии) и др. В основе подобных инфекций лежит формирование биопленок, которые затрудняют микробиологическую диагностику инфекции и ее лечение в связи с антибиотикорезистентностью микроорганизмов в биопленке. Подробно представлены данные по инфекциям в ложе эндопротеза, их этиологии, подходам к диагностике и лечению.

Ключевые слова: девайс-ассоциированные инфекции, перипротезные инфекции, биопленки, антибиотикорезистентность

\section{Информация об авторах:}

Ирина Н. Петухова, e-mail: irinapet@list.ru

Анатолий В. Соколовский, e-mail: avs2006@mail.ru

Злата В. Григорьевская, e-mail: zlatadoc@list.ru

Наталия С. Багирова, e-mail: nbagirova@mail.ru

Инна В. Терещенко, e-mail: in. ter68@inbox.ru

Геннадий В. Варлан, e-mail: varlangv@gmail.com

Виктория В. Агинова, e-mail: avkn@mail.ru

Наталья В. Дмитриева, e-mail: prof.ndmitrieva@mail.ru

В последние десятилетия увеличилось использование в медицине различных конструкций и устройств (англ. device), а именно имплантов, сеток, стентов, катетеров и др. В то время как биомеханические свойства конструкций улучшаются, серьезной проблемой остается развитие девайс-ассоциированных инфекций.

Их особенностью является образование биопленок, в которых персистируют микроорганизмы в окружении внеклеточного полимерного вещества (матрикса). При этом сами бактерии могут составлять лишь 5 - 35\% массы биопленок [2].
Матрикс представляет собой смесь таких веществ, как липополисахариды, гликопротеиды, протеогликаны, нуклеиновые кислоты и другие вещества, аналогичные по составу клеточным стенкам бактерий. Матрикс пронизан каналами, по которым циркулируют питательные вещества, ферменты, продукты жизнедеятельности, кислород.

Началом развития биопленок является прикрепление бактерий к поверхности инородного материала. Затем происходит созревание биопленки, во время которого микроорганизмы теряют подвижность, прикрепление стано- 
Таблица 1. Результаты сравнительного изучения антибиотикорезистентности планктонных и биопленочных бактерий (цит. по [2])

\begin{tabular}{llcc} 
Микроорганизмы & Антибиотик & В жидкой среде, МИК*, мкг мл & 2 \\
Staphylococcus aureus & Ванкомицин & 2 & 20 \\
\hline Escherichia coli & Ампициллин & 8 & 512 \\
\hline Burkholderia pseudomallei & Цефтазидим & 0,063 \\
\hline Streptococcus sanguis & Доксициклин & 800 \\
\hline
\end{tabular}

*МИК - минимальная ингибирующая концентрация

вится необратимым, слой биопленки утолщается, образуются кластеры микроколоний [2].

Через 9 дней после начала образования биопленки структура кластеров изменяется и начинается процесс дисперсии (распада), во время которого бактерии способны активно покидать биопленку и возвращаться к планктонному образу жизни.

Именно благодаря биопленкам возникают трудности в микробиологической диагностике инфекции (возможность выявления только планктонных микроорганизмов, в отсутствие которых не удается определить этиологию инфекции), а также трудности в лечении (плохое проникновение большинства антибиотиков в биопленки и отсутствие эффекта антибиотиков из-за высокой антибиотикорезистентности микроорганизмов в биопленках) (табл. 1).

Высокая устойчивость к антибиотикам проявляется значениями минимальных ингибирующих концентраций (МИК), которые в десятки и сотни раз превосходят аналогичные значения для планктонных форм микроорганизмов. Для того чтобы это преодолеть, необходимо использовать дозы антибиотиков, во много раз превышающие официально разрешенные дозы, что невозможно из-за развития побочных эффектов.

В табл. 1 показаны различия МИК для планктонных форм микроорганизмов и для биопленок.

Известно, что наиболее часто биопленки образуют стафилококки и синегнойные палочки, но на деле их образование может сопровождать инфицирование практически любым микроорганизмом.

Учитывая сложность проникновения антибиотиков в биопленки, для лечения подобных инфекций предпочтительно использовать антибиотики, обладающие хорошим проникновением в биопленки: даптомицин, макролиды (кларитромицин), фторхинолоны и некоторые другие. Из антимикотиков хорошим проникновением в биопленки отличаются эхинокандины.

Кроме того, хорошо проникают в биопленки и бактериофаги. Правда, решение вопроса о применении последних необходимо предварять определением чувствительности к ним выделенных микроорганизмов. А последнее не всегда возможно при биопленочных инфекциях, так как нередко посевы бывают отрицательными и антибиотики назначаются эмпирически, что невозможно в случае применения бактериофагов.
Помимо этого, воздействие бактериофагов часто невозможно из-за того, что основным способом их введения является прием внутрь (реже - промывание раны, полости), а пропагандируемое специалистами, работающими с бактериофагами, свойство проникать в кровь и мочу, мало доказано.

\section{Перипротезные инфекции}

Развитие инфекций в ложе эндопротеза в ортопедии колеблется от $1,5 \%$ до $2,5 \%$, а в онкоортопедии по разным данным составляет 8,5-10\% и более. При выполнении первичных ревизионных операций 15-20\% осуществляются по поводу инфицирования протезов $[5,6]$.

Риск перипротезной инфекции наиболее велик в течение первых 2 лет после установки эндопротеза, однако он остается пожизненно и связан с образованием биопленок. Наиболее частыми возбудителями этих инфекций являются стафилококки, но ими этиологическая структура перипротезных инфекций не ограничивается (табл. 2).

Грамотрицательные микроорганизмы и анаэробы чаще связаны с поздними инфекциями, имеющими гематогенное происхождение, и возникают после вмешательств/манипуляций в области ЖКТ или мочевых путей.

Микобактерии и грибы чаще наблюдаются у пациентов в состоянии иммуносупрессии.

Таблица 2. Наиболее частые возбудители инфекций в области эндопротезов по сводным литературным данным (цит. по [5])

$\begin{array}{lc}\text { Микроорганизмы } & \text { Частота выде- } \\ \text { ления }\end{array}$


Таблица 3. Микроорганизмы, выделяемые методом ПЦР при перипротезных инфекциях в случае отрицательных данных посева (цит. по [5])

Прочие* (Brucella; Coxiella burnettii; Lactobacillus spp.; Listeria monocytogenes; Pasteurella multocida; Propionebacterium acnes; Pseudomonas spp.;Serratia marscescens; Staphylococcus spp.; Streptococcus spp.;Trophyrema whippley; Ureaplasma parvum)

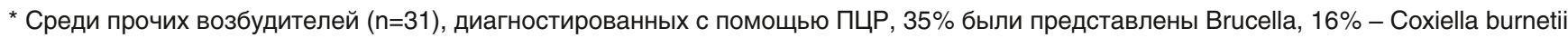

Таблица 4. Демографические характеристики и факторы риска развития инфекций ложа эндопротеза (цит. По [5])

\begin{tabular}{|c|c|c|}
\hline Характеристика & Фактор риска & Частота (\%) \\
\hline Пол & Мужской & $53-58 \%$ \\
\hline Возраст & $>65$ лет & $>50 \%$ \\
\hline ИМТ* & $>25$ & $>50 \%$ \\
\hline Сопутствующие заболевания & $\begin{array}{l}\text { - Хроническая почечная недостаточность } \\
\text { - Дегенеративная болезнь суставов } \\
\text { - Ревматоидный артрит } \\
\text { - Другие поражения суставов (врожденные, асептический некроз, септический артрит, } \\
\text { псориатический артрит, злокачественная опухоль) } \\
\text { - Сахарный диабет } \\
\text { - Заболевания печени } \\
\text { - Сосудистая недостаточность }\end{array}$ & $\begin{array}{l}5 \% \\
53 \% \\
15-20 \% \\
<5 \% \\
8-12 \% \\
3 \% \\
7 \%\end{array}$ \\
\hline Иммуносупрессия & $\begin{array}{l}\text { - Злокачественная опухоль } \\
\text { - Постоянный прием кортикостероидов }\end{array}$ & $\begin{array}{l}17-21 \% \\
11-19 \%\end{array}$ \\
\hline Прочие & $\begin{array}{l}\text { - Медиана «возраста» сустава } \\
\text { - Предшествующий прием антибиотиков } \\
\text { - Инфекции в ложе эндопротеза или хирургическая инфекция в анамнезе } \\
\text { - Предшествующая ревизионная операция }\end{array}$ & $\begin{array}{l}746 \text { дней } \\
53-64 \% \\
3-8 \% \\
5 \%\end{array}$ \\
\hline
\end{tabular}

*Риск инфицирования достоверно увеличивается при каждом повышении ИМТ на 1 балл $(p<0,05)$ [4]

Среди всех инфекций ложа эндопротезов в 5-12\% случаев рост микроорганизмов отсутствует [5]. Однако исследование методом ПЦР позволило выявить возбудителей инфекции даже в случае отрицательных данных посева. 46\% подобных инфекций были вызваны грибковыми патогенами, 43\% - микобактериями, $11 \%$ - другими (атипичными) бактериями (табл. 3).

Неэффективное лечение перипротезной инфекции, вызванной C. burnetii (если она не диагностирована), приводит к неоднократным ревизионным операциям.

Современные стандартные методы микробиологического исследования не позволяют диагностировать инфекцию, вызванную этим микроорганизмом, в 3 из 4 случаев. В связи с этим Million M. et al (2014) предложил исследовать все случаи инфекций ложа эндопротеза с отсутствием микробиологического диагноза на предмет возможного инфицирования C. burnettii или Brucella методом ПЦР [4].

Эти микроорганизмы могут также обнаруживаться при культуронегативном эндокардите. С другой стороны, Chlamydia и Bartonella, которые могут обнаруживаться при культуронегативном эндокардите, не обнаруживались при инфекциях в ложе эндопротеза.

Pasteurella multocida, Lactobacillus spp., Ureaplasma parvus и Serratia marscescens также вызывали инфекции эндопротеза, которые трудно диагностировать и которые не имели подтверждения микробиологическими методами.

Следует отметить, что бактерии, образующие биопленки и вызывающие микробиологически недоказанные инфекции, являются независимым фактором риска неэффективности лечения. Т. е. неэффективная диагностика приводит к неэффективности лечения.

Помимо вида и свойств микроорганизма, развитию инфекций ложа эндопротеза способствует ряд факторов со стороны пациента (табл. 4).

Кроме перечисленных в табл. 4 факторов, также в развитии инфекций в области эндопротеза определенную роль могут играть: почечная недостаточность (клиренс креатинина $<30$ мл/мин), гипоальбуминемия $(<34$ г/л) и абсолютное число лимфоцитов <1500×109/л [5]. Maier G.S. et al. (2014) также обнаружили достоверную зависимость между дефицитом витамина Д и инфекцией ложа эндопротеза $(\mathrm{p}<0,001)$ [3].

Достоверное влияние могут также оказывать предшествующие ревизионные операции, длительность операции свыше 2,5 часов, поверхностные раневые инфекции, дренирование раны, высокий индекс по Американской шкале анестезиологов (ASA). При этом последние три фактора 
были статистически достоверными при значениях $\mathrm{p}$, равных 0,007, 0,001 и 0,05 соответственно [5].

Одним из важнейших маркеров инфекции является C-реактивный белок, который в исследованиях превышал 10 мг/л при всех инфекциях эндопротеза [1,5].

Чувствительность и специфичность исследования числа лейкоцитов в аспирате (более $1,7 \times 109 /$ л) составляет $90 \%$ и $88 \%$, соответственно. А чувствительность и специфичность диагностики методом ПЭТ составляет $82 \%$ и $87 \%$ соответственно [5].

Улучшению микробиологической диагностики инфекций ложа эндопротеза может служить сонификация (ультразвуковая обработка) эксплантированного протеза. Положительные результаты при сонификации временно устанавливаемых спейсеров, удаляемых при двухэтапных ревизионных операциях, являются прогностическим фактором реинфекции и характеризуются 50\%-ной частотой неэффективности лечения [5].

Методом сонификации можно обнаруживать стафилококки, имеющие малые варианты колоний (англ. - small colony variants - SCV), которые трудно обнаружить традиционными микробиологическими методами.

Современные рекомендации по лечению инфекций в ложе эндопротеза доказанной этиологии предполагают проведение 3-6-месячной антибиотикотерапии в дополнение к 2-этапной ревизионной операции $[1,5,6]$. Среди наиболее часто используемых на западе стартовых антибиотиков - рифампицин, фторхинолоны (в случае MRSA - рифампицин и ванкомицин или рифампицин и линезолид). Однако следует учитывать, что рифампицин - антибиотик, используемый в лечении туберкулеза, и его желательно не использовать широко в хирургической практике. Кроме того, к рифампицину в процессе лечения нередко развивается резистентность.

В настоящее время также появились другие антибиотики - даптомицин, тигециклин.

В НМИЦ онкологии им. Н. Н. Блохина имеется положительный опыт использования даптомицина с целью лечения инфекций в ложе эндопротеза. Препарат назначался пациентам на срок от 1 до 3 недель в монотерапии либо в комбинации с другими антибиотиками. Дозы препарата варьировали от 6 до 10 мг/кг/сутки. Переносимость была хорошей.

Еще одним новым препаратом, проникающим в биопленки, является тигециклин. Несмотря на то, что для этого препарата инфекции кожи и мягких тканей являются одним из основных показаний, тем не менее, он практически не используется для лечения инфекций в ложе эндопротеза. Причиной этого, с одной стороны, является широкий спектр действия тигециклина, который позволяет использовать препарат для лечения в первую очередь мультирезистентных грамотрицательных инфекций, а с другой стороны, наличие в настоящее время достаточно широкого спектра антибиотиков, активных в отношении грамположительных инфекций, помимо тигециклина.

Таким образом, перипротезные инфекции, наряду с другими девайс-ассоциированными инфекциями, имеют важное значение в клинической практике. Принципиально важным является установление этиологии процесса микробиологическим методами, а при невозможности - использование ПЦР, сонификации. Правильная диагностика перипротезной инфекции - залог ее успешного лечения.

\section{Литература • References}

1. Нисиченко Д. В., Дмитриева Н. В., Петухова И. Н., Соколовский В.А., Григорьевская З. В., Алиев М. Д. Инсеекционные осложнения эндопротезирования у больных со злокачественными опухолями костей // В кн: «Послеоперационные инфекционные осложнения: диагностика, лечение, профилактика. Практическое руководство» под ред. Н.В. Дмитриевой, И. Н. Петуховой, 2013 г., Москва, «Практическая медицина», стр. 61-88.

2. Чернявский В.И. Бактериальные биопленки и инфекции (лекция) // Ann Mechnikov Institute, 2013, 1; 86-90.

3. Maier GS, Horas K, Seeger JB, Roth KE, Kurth AA, Maus U. Is there an association between periprosthetic joint infection and low vitamin D levels // Int Orthop 2014; 38 (7): 1499-504.

4. Million M., Bellevegue L., Labussiere AS. Culture-negative prosthetic joint arthritis related to Coxiella burnettii // Am J Med $2014 ; 127$ (8) 786. e7-10.

5. Monisha S. Parikh, Suresh Antony. A comprehensive review of diagnosis and management of prosthetic joint infections in the absence of positive cultures.// J Infect Public Health, 2016; 9: 545-556.

6. Zimmerli W. Orthopaedic device-associated infection //Clin Microbiol and Infect Dis CMI; 18: 1160-1161. 